\title{
Transição e (In)Adaptação ao Lar de Idosos: Um Estudo Qualitativo
}

\author{
Carla Gomes Faria ${ }^{1}$ \\ Macedo Peixoto Carmo \\ Instituto Politécnico de Viana do Castelo
}

\begin{abstract}
RESUMO - Um dos contextos de envelhecimento é o lar de idosos, mas pouca atenção tem sido dedicada ao processo de institucionalização, particularmente numa perspectiva desenvolvimental e ecológica. Assim, desenhamos um estudo qualitativo com o objectivo de explorar a experiência de transição e adaptação ao lar de 15 idosos institucionalizados há mais de um ano. Os participantes foram entrevistados e a análise de conteúdo permitiu identificar um tema comum - Vivência da Institucionalização, que integra três domínios: Tomada de decisão, Processo de institucionalização, e Posicionamento face à institucionalização. Os resultados sugerem que a institucionalização constitui uma transição que nem sempre resulta em adaptação e que o envolvimento do idoso na tomada de decisão e as características ambientais são fundamentais neste processo.
\end{abstract}

Palavras-chave: envelhecimento, transição, adaptação, institucionalização em lar, gerontologia social

\section{Transition and (In)Adaptation to Nursing Home: A Qualitative Study}

\begin{abstract}
One of the aging contexts is the nursing home, but little attention has been dedicated to the institutionalization process, particularly from a developmental and ecological perspective. Thus, we designed a qualitative study to explore the experience of transition and adaptation of 15 elderly who were institutionalized in a nursing home for more than a year. Participants were interviewed and content analysis identified a common theme - Experience of Institutionalization, which integrates three domains: Decision making, Process of institutionalization, and Positioning to institutionalization. The results suggest that institutionalization is a transition that does not always result in adaptation, and that the elderly participation in the decision making and the environmental characteristics are fundamental in this process.
\end{abstract}

Keywords: aging, transition, adaptation, institutionalization in nursing home, social gerontology

O envelhecimento, enquanto processo, integra mudança e continuidade, sendo que os acontecimentos de vida podem assumir-se como centrais em todo este processo pelos desafios, exigências e potencialidades que colocam à pessoa (Baltes, Lindenberger, \& Standinger, 2006). No entanto, não é possível compreender esse processo, altamente complexo e heterogéneo, sem uma leitura contextualizada em termos ambientais, sociais, culturais e históricos. Nesse contexto, a institucionalização em lar pode constituir um acontecimento de vida com potencial para exigir a mobilização de recursos intra e interpessoais, e com fortes implicações para a qualidade da trajetória desenvolvimental em termos de (in)adaptação. A compreensão das dinâmicas envolvidas no processo institucionalização em lar tem-se mostrado muito relevante, quer pelas implicações para a qualidade de vida dos idosos integrados no lar, quer das próprias estruturas residenciais que recebem essas pessoas. Nesse sentido, importa analisar a transição casa-lar a partir de uma perspectiva múltipla em termos conceptuais que potencie a compreensão de dimensões individuais (e.g., recursos, estratégias intrapessoais) e contextuais/ambientais (e.g., características do ambiente lar).

Assumindo uma leitura contextual-dialética (Baltes e tal., 2006) do desenvolvimento e envelhecimento humano, parece-nos fundamental considerar o fenómeno casa-lar a partir de uma análise transacional que considere aspetos da

1 Endereço para correspondência: Avenida Capitão Gaspar de Castro, Apartado 513, Viana do Castelo, Portugal. CEP: 4900908.E-mail: cfaria@ese.ipvc.pt pessoa/idoso (ex., a experiência de vida prévia, processo de tomada de decisão, nível de controlo sobre a vida pessoal), do processo de transição (ex., contínuo, abrupto), e do ambiente lar de idosos (ex., características físicas, serviços disponibilizados e recursos humanos).

A resposta social "lar de idosos" deriva das antigas instituições asilares e constituiu a primeira resposta social de apoio aos mais velhos. Segundo Goffman (1996), essas instituições faziam parte das também designadas instituições totais, definindo-as como "um local de residência e trabalho onde um grande número de indivíduos com situação semelhante, separados da sociedade mais ampla por considerável período de tempo, levam uma vida fechada e formalmente administrada" (p. 11). Assim, tais instituições obedecem a regras e normas instituídas, dando cumprimento aos seus objetivos, sem atender aos interesses ou idiossincrasias das pessoas que lá permanecem. Nesse sentido, para Alcântara (2004) institucionalizar é confiar alguém aos cuidados de uma instituição especializada, no caso dos idosos aos lares. Assim, um idoso ao mudar-se para o lar terá de se adaptar a um novo esquema de vida, a uma rotina diferente, com pessoas distintas, horários préestabelecidos para comer, dormir, tomar banho. Essas regras são estabelecidas de acordo com as políticas da instituição, pelo que de alguma forma o idoso ao ser institucionalizado perde um pouco da sua identidade, tendo de se adaptar a uma nova forma de vida, a um ambiente diferente, a um novo espaço, e a conviver com pessoas diversas. Nesse contexto, o modelo de expropriação proposto por Goffman (1996) assume-se como uma grelha de leitura útil para compreender 
a experiência de institucionalização, especificamente, o modo como a instituição se "impõe" ao idoso. Ou seja, a partir do momento em que o idoso entra na instituição lar, ocorre um processo de perda progressiva de grande parte das dimensões que caracterizavam a sua vida e identidade, nomeadamente, direitos, papéis, relações e liberdades. Apesar da leitura de Goffman se referir a instituições como prisões ou hospitais psiquiátricos, da década de 1960, com características muito específicas, parece-nos possível ajustar a proposta do autor à instituição lar de idosos, na medida em que também o lar está estruturado no sentido de assegurar a guarda de pessoas, frequentemente em situação de dependência ou limitação e, por isso, mais vulneráveis à pressão ou controlo totalitário imposto pelo funcionamento altamente estruturado e rígido das mesmas. A investigação dentro dessa leitura tem reunido evidências que a reforçam. Barenys (1990), no âmbito de um estudo sobre os lares em Espanha, considera que estes, enquanto instituições totais, são uma combinação entre "a comunidade residencial e a organização regulamentada" ( $p$. 98). O grau de isolamento do idoso face ao exterior e o seu controlo sobre a sua vida e o seu dia a dia dependem quer da política organizacional da instituição, quer das características individuais do mesmo, nomeadamente o nível de autonomia física e psicológica e a intensidade dos vínculos relacionais com elementos exteriores à instituição, particularmente a família. Também em Portugal, Guedes (2008) desenvolveu um estudo qualitativo num lar de um grande centro urbano com a finalidade de avaliar os efeitos específicos que a instituição produz sobre a identidade dos idosos. A autora parte do princípio de que o processo de institucionalização conduz a perda de autonomia, ruptura com a vida prévia e com muitos dos laços afetivos importantes para o idoso. Com base em observações e entrevistas a idosos residentes no lar, Guedes analisou o processo de integração no lar e as estratégias de adaptação que os idosos desenvolveram, tendo identificado quatro tipos de estratégias de adaptação: (1) retraimento sobre si próprio, (2) anonimato, (3) diferenciação, e (4) conversão. Globalmente, os resultados reforçam essa leitura em que a instituição lar se sobrepõe ao idoso, anulando a sua identidade, limitando a sua liberdade, controlo e poder.

Do ponto de vista do processo de institucionalização, Graeff (2007) refere que os primeiros tempos de institucionalização são marcados por um processo de ajustamento, durante o qual as ambiguidades e o estigma da nova condição são vividos em articulação com uma experiência de aprendizagem de novos padrões culturais. Fazer parte da cultura institucional significa compreender e incorporar um conjunto complexo e hierarquizado de formas de pensar e agir, que são articuladas ao próprio ritmo das relações estabelecidas em cada espaço social habitado. Assim, apesar do aumento expressivo das instituições "lar" e do reconhecimento de que a institucionalização pode até oferecer possibilidade de acolhimento e de expressão pessoal, viver no lar não é o mesmo que viver numa família onde os laços do passado e do presente estão vivos e são compartilhados afetiva e socialmente (Bula \& Mediondo, 2004; Ferreira, 2003; Santini, 2000).

A investigação no âmbito da institucionalização tem reunido evidências que permitem identificar as principais causas ou motivos que a desencadeiam. Globalmente, destacam-se motivos como dependência, perda de autonomia, agravamento do estado de saúde, ineficácia da sua rede de interações, conflitualidade nas relações familiares, divergência de interesses, morte do cônjuge, isolamento e solidão, dificuldades financeiras, degradação da habitação ou a sua incompatibilidade com as perdas funcionais e de mobilidade (Pimentel, 2001; Reed, Cook, Sullivan, \& Burridge, 2003; Sousa, Figueiredo, \& Cerqueira, 2004).

No caso específico do envelhecimento e da institucionalização em lar, grande parte da conceptualização existente faz-se em paralelo com a literatura relativa ao mesmo fenómeno em outros domínio ou períodos de vida. No entanto, a investigação sobre esse processo é ainda escassa, assim como a sua conceptualização à luz de quadros teóricos específicos do envelhecimento e da gerontologia social. Da análise da literatura existente, o aspecto que parece mais evidente é que neste processo "jogam" claramente duas dimensões: uma relativa à pessoa e outra relativa ao contexto lar.

Na década de 1960, a partir da necessidade de compreender o processo de institucionalização, surgiram modelos e teorias que se enquadram na abordagem ecológica, dando início a estudos sobre diversos fatores ambientais que podem afetar o comportamento das pessoas idosas no lar, clarificando a natureza das relações entre o ambiente e o comportamento na velhice (Guedes, 2008).

Lawton (1989) foi um dos primeiros a direcionar o interesse para a interação pessoa-ambiente na velhice, desenvolvendo o Modelo Ecológico da Competência-Pressão (Lawton \& Nahemow, 1973; Lawton, 1977). O Modelo assenta em dois conceitos nucleares - competência e pressão ambiental. A competência é definida pelo autor como "o limite teoricamente superior da capacidade do indivíduo para funcionar nas áreas da saúde, biológica, a sensaçãopercepção, e conduta motora, e a cognição" (Lawton, 1975, p. 23). Já a pressão ambiental refere-se ao grau de exigência que o ambiente exerce sobre as capacidades sociais e físicas da pessoa, quer do ponto de vista real, quer subjetivo. De acordo com o referido modelo, os aspetos que predizem a adaptação ambiental dos idosos são a sua competência individual e a pressão exercida pelo meio ambiente em que se encontram. Exigências excessivas do meio face às competências, provocam resultados negativos e stress, sendo que exigências inadequadas conduzem à perda de competências por falta de uso. Nesse sentido, uma pessoa mais competente suporta uma maior pressão do meio, permanecendo adaptada. Para Lawton (1975), o ambiente mais favorável seria aquele cujo nível de exigência se situa no limite do nível máximo de competência. O autor avançou posteriormente com a hipótese da "docilidade ambiental" para salientar o papel do ambiente na compensação das perdas inerentes ao envelhecimento, isto é, à medida que o nível de competência pessoal decresce, mais os fatores ambientais influenciam o comportamento e a capacidade adaptativa (quer positiva, quer negativamente) (Paúl, 2005). A este propósito Lawton (1975) considera que o ambiente pode exercer três tipos de funções: (1) manutenção, (2) estimulação e (3) suporte. A manutenção refere-se ao papel de constância e previsibilidade que o ambiente deve assegurar (ex., conferir identidade aos ambientes, preservar os significados cognitivos e afetivos do 
ambiente). Já a função estimulação diz respeito à capacidade do ambiente apresentar novas fontes de estímulos capazes de estimular comportamentos novos ou esbatidos. Finalmente, a função suporte significa compensar a redução ou perda de competências, através, por exemplo, da eliminação de barreiras ou da disponibilização de mecanismos compensatórios. Neste contexto, o ambiente ideal é aquele que faz apelo ao uso das capacidades residuais da pessoa "a zona de desempenho potencial máximo" (Paúl, 2005, p. 252). O Modelo Ecológico de Competência - Pressão abriu o campo da investigação nesse domínio, tendo-se seguido a formulação de outros modelos que partilham pressupostos e concepções (e.g., Carp \& Carp, 1984; Kahana, Liang, \& Felton, 1980).

A investigação relativa à importância do papel do ambiente no apoio às pessoas mais velhas inclui trabalhos sobre a adaptação do ambiente do lar para identificar e reduzir perigos e para ajudar nas atividades da vida diária (Gill, Robinson, Williams, \& Tinetti, 1999). A partir de estudos sobre a ecologia ambiental, Groger (1995) concluiu que a capacidade das instituições conseguirem fazer com que os idosos se sintam em casa depende de três fatores: (1) circunstâncias de mudança relativas ao tempo disponível para antecipação de mudança, (2) definição de lar para os residentes, e (3) continuidade alcançada depois da mudança para o lar.

A institucionalização pode constituir-se como uma transição, na medida em que a saída de casa e o ingresso em lar confronta o idoso com potenciais perdas e ganhos em termos intra e interpessoais, com fortes implicações para o seu funcionamento individual. Neste contexto, o modelo de Schlossberg e colaboradores (Schlossberg, 1981; Schlossberg, Water, \& Goodman, 1995) que descreve as transições nos adultos e idosos, apoiando-se numa leitura do desenvolvimento humano que é simultaneamente contextual e de ciclo de vida é um quadro útil para ler o processo de transição casa-lar. A transição decorre sempre de um acontecimento ou não acontecimento e resulta em mudanças nas concepções acerca do self e do mundo (Schlossberg, 1981). Nesse sentido, uma transição é caraterizada habitualmente por uma organização de vida e por uma nova expressão do self (Schlossberg, 1981). A forma como cada pessoa lida com a transição e constrói um resultado (in)adaptativo está relacionada com uma diversidade de condições que, na perspectiva de Schlossberg et al. (1995), se podem tipificar em: (1) variáveis da situação, (2) variáveis do self, (3) variáveis de suporte e (4) variáveis de estratégia. Assim, importa considerar até que ponto a situação que desencadeia a transição é prevista, em que momento de vida ocorre, o nível de controlo da pessoa sobre a situação, e o tipo e duração de mudança de papéis a que obriga. Neste contexto, a institucionalização poderá ser um acontecimento antecipado, mas que não tem um momento pré-determinado na vida do idoso para ocorrer e, em muito caso, não é desejado nem esperado. Por outro lado, o nível de controlo do idoso sobre o processo e as mudanças subjacentes, particularmente na vida pós-institucionalização, é muito reduzido. Além disso, essas mudanças têm um carácter permanente, ocorrem numa fase da vida em que frequentemente a pessoa já se encontra vulnerável devido a outras transformações (ex., perdas funcionais, relacionais) e acarreta, habitualmente, perdas de papéis de vida significativos. Assim, do ponto de vista das variáveis da situação, a institucionalização reúne muitas condições para se constituir numa transição altamente desafiante. Já as variáveis do self referem-se a características pessoais, demográficas e psicológicas da pessoa envolvida na transição. Características como idade, género, estatuto socioeconómico, etnia, estatuto de saúde são muito relevantes na capacidade individual para gerir a transição. No caso da institucionalização, estão em causa pessoas mais velhas, por vezes muito velhas, maioritariamente do género feminino, com um estatuto de saúde debilitado e geralmente com dificuldades financeiras. Todas essas características podem colocar o idoso em maior vulnerabilidade e ou desvantagem para lidar com as exigências associadas à institucionalização. Por fim, a variável de suporte refere-se à rede de suporte social e à sua capacidade de apoiar a pessoas, e a variável estratégia diz respeito ao tipo de estratégias de coping a que recorre. No caso dos idosos, decorrente dos efeitos do envelhecimento, é frequente que a sua rede social seja limitada, o que também condiciona a capacidade da rede para ajudar e, além disso, a institucionalização usualmente representa um corte com essa rede, reduzindo ainda mais esse recurso fundamental para a adaptação à transição. Assim, a capacidade individual para lidar com as mudanças inerentes à institucionalização decorrem da conjugação de uma diversidade de condições do idoso, sendo o resultado desse processo de transição altamente heterogéneo. Ou seja, a transição casa-lar constitui um tipo particular de mudança em que o idoso experimenta uma descontinuidade na sua vida, envolvendo quer a tomada de consciência pessoal das novas exigências e a consequente necessidade de desenvolvimento de novas competências, quer a adoção de respostas comportamentais de ajustamento a essas exigências (Brammer \& Arego 1981).

Apesar de nem sempre desejada, a institucionalização em lar é um acontecimento com alguma frequência para os mais velhos. Esse acontecimento tem sido conceptualizado como um processo que envolve geralmente um conjunto de tarefas, como por exemplo escolher o lar, preparar a saída de casa e a adaptação e integração à nova residência. Assim, nos últimos anos tem-se procurado compreender de que modo o envolvimento do idoso na tomada de decisão relativamente à institucionalização tem implicações para o processo de transição e adaptação. Um dos trabalhos de maior relevância nesse domínio foi conduzido por Reed et al. (2003) que, com recurso a entrevistas, procuraram compreender o modo como os idosos geriam as decisões sobre a institucionalização. Os resultados permitiram identificar quatro tipos de tomada de decisão relativamente à institucionalização: (1) preferencial, (2) estratégica, (3) relutante e (4) passiva.A tomada de decisão preferencial caracteriza-se por o próprio exercer o direito de decisão; ocorre perante alterações nas circunstâncias de vida que levam o idoso a ponderar a ida para o lar como a melhor alternativa. É importante para o idoso ter acesso às informações necessárias para fazer uma escolha informada sobre as alternativas existentes.A tomada de decisão estratégica exprime um planeamento da institucionalização por parte do idoso ao longo da sua vida, o que facilita a adaptação à opção encontrada. É expressa em alguns comportamentos, tais como proceder à inscrição 
como antecedência no lar, tornar-se sócio de uma instituição iniciando pagamentos prévios, visitar lares tentando descortinar aquele que mais gostaria de habitar. Essa postura é mais frequente em pessoas solteiras, viúvas e/ou sem filhos ou, se os têm, vivem longe e/ou não tem condições para cuidar do idoso. A tomada de decisão relutante refere-se à situação em que o idoso resiste ou discorda ativamente da entrada num lar. É a circunstância mais dolorosa, pois o idoso é forçado, pela família ou por profissionais, a adotar uma opção que não é a sua. A tomada de decisão passiva caracteriza-se pelo facto de o encaminhamento para o lar decorrer da decisão de outros sobre o nível de cuidados requeridos, sendo que o idoso obedece sem questionar esta orientação. Esse tipo de tomada de decisão acontece geralmente em dois casos: idosos com demência ou idosos resignados/passivos. A qualidade da adaptação tende a estar associada ao tipo de tomada de decisão, sendo que decisões do tipo preferencial ou estratégico facilitam a adaptação, contrariamente às decisões do tipo relutante ou passiva.

Face ao exposto, o presente estudo tem como objetivo compreender a experiência de transição e adaptação ao lar na perspectiva das pessoas mais velhas.

\section{Método}

\section{Contexto e Participantes}

Participaram no estudo 15 idosos institucionalizados há mais de um ano num lar de uma cidade do interior da região norte de Portugal. Trata-se de uma instituição localizada no núcleo urbano da cidade, com boas acessibilidades em termos de transportes, bem como de serviços (culturais, de saúde, lazer, entre outros). Do ponto de vista organizacional, apresenta um funcionamento flexível que permite grande liberdade aos residentes em termos de entradas e saídas ao longo do dia, bem como de visitas. No momento de admissão, o idoso pode fazer-se acompanhar de objetos pessoais. Além disso, o lar disponibiliza uma diversidade de serviços: culturais, de lazer, saúde e sociais.

A maioria dos participantes é do género feminino $(n=11)$, solteira $(n=8)$, sem filhos $(n=9)$, com idades compreendidas entre os 67 e os 85 anos de idade e com mais de nove anos de escolaridade. O tempo de permanência no lar varia entre 18 meses e 23 anos.A participação no estudo foi voluntária, tendo-se definido como critérios de participação estar integrado no lar há pelo menos um ano, não apresentar problemas mentais e/ou cognitivos ou dificuldades de comunicação verbal.

\section{Procedimentos de recolha de dados}

A recolha de dados realizou-se segundo os princípios éticos propostos pela Associação Americana de Psicologia (APA, 2010). Paralelamente, o projeto de investigação foi aprovado pela Comissão Científica do Mestrado em Gerontologia Social do Instituto Politécnico de Viana do Castelo. Depois de obter a autorização para a realização do estudo no lar, foram apresentados aos participantes o objectivo do estudo, uma breve descrição do mesmo, bem como a garantia de confidencialidade, anonimato e privacidade da informação recolhida. De seguida, os participantes deram o seu consentimento informado para participar no estudo. Os dados foram recolhidos através de entrevista semiestruturada, cujo guião foi construído especificamente para o estudo, sendo composto por questões abertas, destinadas a conhecer a experiência do entrevistado. $\mathrm{Na}$ elaboração do guião procurou-se atender a orientações específicas no sentido de adequar o mesmo às características dos participantes (Wenger, 2001), nomeadamente ao nível da linguagem utilizada, extensão das questões e do guião, sequenciação das questões entre outras. As entrevistas foram realizadas na instituição num espaço que assegurava as condições físicas para a realização das mesmas, bem como condições de privacidade e segurança dos participantes, tendo sido registadas em áudio e transcritas verbatim.

\section{Procedimentos analíticos}

As entrevistas foram sujeitas a análise de conteúdo, utilizando o procedimento de análise de conteúdo proposto por Creswell (2009). Esse processo de análise que tem por finalidade dar um sentido a dados, neste caso texto, envolve (1) preparar os dados para análise, (2) conduzir diferentes análises, (3) perceber profundamente os dados, (4) representar os dados e (5) interpretar o seu significado. No que se refere à codificação, neste estudo foi usada uma abordagem indutiva, tendo como unidade de análise a frase. $\mathrm{O}$ processo de análise de conteúdo foi conduzido em simultâneo com a realização das entrevistas até se atingir a saturação de dados. A codificação das entrevistas foi realizada por um juiz, sendo que inicialmente foram codificadas cinco entrevistas de modo independente por esse juiz e um outro especialista nesse procedimento, como estratégia de assegurar o rigor no processo de codificação. As restantes 10 entrevistas foram cotadas pelo primeiro juiz e a sua codificação validada pelo referido especialista que assumiu o papel de auditor/ especialista.

\section{Resultados}

Da análise de conteúdo realizada foi possível constatar que a experiência de transição e adaptação ao lar vivenciada pelos participantes organiza-se em torno de um tema comum - Vivência da Institucionalização, que agrega três domínios constituídos por um número variável de categorias: Tomada de decisão, Processo de institucionalização e Posicionamento face à institucionalização. Assim, a dimensão transversal à experiência de transição e adaptação ao lar dessas pessoas mais velhas parece ser o modo como cada uma viveu esse acontecimento, destacando particularmente a fase que antecedeu a entrada para o lar e a fase posterior. Passaremos a descrever cada um dos domínios, procurando ilustrar com estratos das entrevistas que permitam clarificar as descrições apresentadas. 
Tomada de Decisão. A institucionalização em lar implica uma tomada de decisão acerca do futuro. Ou seja, de acordo com a experiência dos nossos participantes, o processo de tomada de decisão precede a institucionalização. No entanto, o modo como esta decisão é tomada e o papel e envolvimento do idoso na decisão parecem revestir-se de particular importância para os mesmos. Alguns participaram ativamente na decisão, tendo a entrada para o lar sido algo que planejaram ao longo da vida:

"Eu nunca pensei noutro lar se não neste, sempre pensei vir. Estive seis anos à espera que me chamassem, vinha todos os anos renovava o pedido, portanto quem esperou seis anos ficou a dar saltos de contente quando ouvi "sim"!" (ID03)

Já no caso de outros participantes, a decisão foi assumida por outras pessoas, maioritariamente familiares, sendo a decisão aceite passivamente pelo idoso:

"Puseram-me aqui..., trouxeram-me para aqui ... Contrariada! Não, não, não não, não, não, tive sempre medo..." (ID01)

A institucionalização foi desencadeada essencialmente por motivos relacionados com problemas de saúde do próprio ou do familiar com quem viviam, sentimentos de solidão, problemas habitacionais, ou ausência de retaguarda e apoio informal.

"Foi a morte da minha irmã com quem vivia, vivíamos as duas e ela morreu de repente, e pronto!" (ID06)

"Porque achei que mais tarde ou mais cedo teria que vir, ia ficar só e portanto quis escolher a tempo, a ser eu a escolher." (ID07)

"Tinha muitas escadas, trinta e tal escadas sempre para subir. Eu num podia, por causa da coluna, porque eu foi operado à hérnia discal e num podia esforçar!'(ID013)

Mas independentemente do grau de participação ou dos motivos subjacentes, a tomada de decisão é identificada pelos idosos como acompanhada por sentimentos intensos e muito diversificados. Alguns recordam esse processo como sendo pautado por sentimentos positivos e agradáveis (ex., liberdade, alegria, satisfação pessoal):

"Senti-me bem, pronto, estou como se fosse na minha casa, agora a minha casa é isto, é este quarto é a minha casa, de maneira que quando venho, vou para a minha casa."

“(...) poder decidir em termos de procurar uma distração, procurar um passeio quer dizer... hum...senti que aqui poderia ser uma pessoa diferente, com mais tomadas de posição, diferente, com mais liberdade!'(ID06)

No entanto, para outros participantes, a decisão de entrada no lar foi geradora de sentimentos negativos e perturbadores:

"Eu senti-me revoltada; frustrada ... uma revolta terrivel, com raiva, e não me habituei! Sinto-me revoltada, revoltada, revoltada (...)"(ID01)

"Não me quero recordar, foi um dia muito, muito, muito infeliz, muito triste, deixei a minha casa e a as minhas coisas..."(ID011)

Processo de Institucionalização. A institucionalização em lar foi vivida pelos participantes como um processo gradual, constituído por diferentes momentos, e experienciado de forma muito idiossincrática. O foco central deste domínio é o modo como o idoso experienciou a entrada no lar, particularmente o que constituiu obstáculo ou dificuldade, o que ajudou ou facilitou. Do ponto de vista processual, todos os participantes identificam o período pré e pós institucionalização, pois o modo como as suas vidas, relações e contextos estavam organizados eram claramente diferentes antes e depois da entrada para o lar. Aspectos do ambiente como localização do lar, organização interna, normas de funcionamento, e qualidade dos serviços foram apontados como tendo facilitado o processo de transição e adaptação ao lar. Ou seja, como o lar se localiza no centro da cidade, os idosos facilmente se deslocam a locais e espaços que frequentavam previamente à institucionalização; além disso, a flexibilidade das regras de funcionamento permite aos idosos entrar e sair livremente ao longo do dia, receber livremente visitas, fazer-se acompanhar de objetos pessoais na entrada para o lar; por outro lado, a diversidade de serviços e atividades proporcionados e a formação dos colaboradores contribui para a satisfação de necessidades e interesses dos idosos, aumentando o seu bem-estar.

"Porque quero estar no centro da cidade e quero fazer a mesma vida que fazia até agora."(ID07)

"O funcionamento do lar, nesse ponto... é bom ... porque nós temos a liberdade de entrar e sair... aqui só temos de cumprir horário para as refeições, de resto, durante o dia, durante a noite gente pode sair, entra à hora que quiser, e nunca ninguém criou problema.(...) porque eu parti antecipadamente eu mobilei aquele meu ambiente, eu passei a viver... porque eu podia trazer os móveis da nossa casa, eram móveis antigos."(ID02)

Mas, se alguns participantes encontraram fontes de suporte ou facilitadores no processo de adaptação, outros identificaram dificuldades ou obstáculos nesse processo. A vivência de sentimentos de isolamento e solidão, perda de identidade, dificuldades de integração e interação com outros residentes, e conflitos com alguns colaboradores constituíram as principais dificuldades. Assim, alguns participantes consideraram que a partir do momento em que entraram para o lar desenvolveram a percepção de alguma perda de identidade, pois todos estavam identificados por um número de processo, o que lhes provocava a sensação de se terem tornado "invisíveis" enquanto pessoas com interesses, necessidades e uma história de vida.

"A palavra propriamente a palavra lar...assusta-me muito... Oh, está no lar, como quem diz, está para lá arrumado. Já não é ninguém! Não somos números, somos pessoas! Aquilo incomodava-me bastante. E que é que eu fazia? Levava o papel do pagamento, e punha na frente dela, só pra não me pedir o número. Porque me incomodava muito. Incomodava. Porque eles têm por obrigação, todos os empregados da casa, saberem o nosso nome (...)"(ID011)

Já para outros participantes, as saudades face à vida prévia e o sentimento de solidão decorrente do processo de institucionalização foram as maiores dificuldades. O corte com a vida construída e vivida durante décadas, a perda de relações interpessoais importantes ou de contacto e interação com lugares, objetos ou situações provocou um sentimento de perda e abandono que dificultou muito a adaptação ao novo contexto e condição de vida.

"Eu tinha saudades da minha casa. Tinha naturalmente saudades..."(ID04)

"Custou-me num é? Custou-me a conhecer as pessoas e custou-me adaptação, custou-me ao princípio, custou-me 
um bocado, era tudo diferente. Já não podia estar com os meus amigos de antes, já não tinha a minha casa, as minhas coisas. Era tudo novo. Tudo, tudo..."(ID05)

Por fim, certos participantes assinalaram as rotinas estruturadas como tendo exigido maior esforço de adaptação, retirando-lhes mesmo liberdade de escolha ou até controlo sobre a sua própria vida.

"Mas aqui o que me custou mais foi uma coisa... Foi de manhã levantar-se cedo! E depois não temos escolha, a comida é a mesma para todos, não podemos escolher, temos de comer, levantar, deitar todos à mesma hora. E aí não há escolha, ninguém nos pergunta se queremos ou concordamos.... Tem de ser assim! Deixamos de ser donos de nós...."(ID09)

Como referimos previamente, os participantes contrastam a organização de vida e funcionamento diário pré e pós institucionalização. O que parece emergir do discurso é que para os idosos claramente existiu um "antes" e um "depois" da entrada para o lar, constituindo-se assim a institucionalização como um marcador temporal. Esse processo de dicotomização é de tal forma abrangente que o encontramos mesmo em participantes com histórias de adaptação bem-sucedidas ao lar. Globalmente, a vida préinstitucionalização era caraterizada por liberdade de ação, controlo sobre a vida pessoal, capacidade de decisão, e sentimento de identidade.

"Eu em casa também já estava... saia de manhã às 7 hora e meia para tomar o meu pequeno-almoço às frigideiras, lia o jornal, isto depois de me reformar, lia o jornal, fazia umas compras, e ia para casa, a minha filha é bancaria, a mais nova e a outra também é bancaria. A minha filha mais nova ia almoçar comigo e eu fazia o almoço... almoçávamos as duas, ela ia para o trabalho, e eu ficava em casa, lavava a... arrumava a cozinha e ia dar uma volta, pegava no meu carrinho, às vezes, outra vezes ia a pé, dependia do sítio, decidia a qualquer lado, pegava no carro e ia... ia ver uma prima, ou ia ao centro.’(ID01)

Já o período pós-institucionalização é, para um grupo de participantes, caraterizado pelo corte com o passado, pela perda de relações significativas, por uma visão negativa da sua condição e do futuro.

"Agora não, agora quer dizer, chego aqui não tenho nada que fazer, nem tenho vontade de fazer nada... Sento-me a ver televisão e fico estúpida!'(ID01)

“(...) tinha tanta gente à minha volta, e isso faz-me falta, $e$ tem-me feito mal, tem-me feito mal perder essa, esse convívio que eu tive."(ID014)

No entanto, para outro grupo de participantes o pósinstitucionalização representou uma melhoria de vida, com maior conforto e menor carga de trabalho e esforço.

"Portanto, tive uma sensação de melhoramento... mais conforto... As pessoas também muito abertas, muito delicadas. Agradou-me."(ID04)

“(...) temos aqui tudo, não nos falta nada, sobretudo temos uma coisa importante, independência, e... assim independência, a gente pode entrar e sair quando quiser, não há problema!'(ID012)

Posicionamento face à institucionalização. A informação agregada neste domínio permite perceber que os participantes desenvolveram uma perspectiva sobre o seu próprio processo de entrada no lar, sendo esta pautada por memórias e sentimentos (positivos e negativos), e posicionamento crítico expresso na capacidade de identificar vantagens e desvantagens de viver no lar, bem como de formular orientações de melhoria da instituição e de orientação de novos residentes no processo de adaptação à institucionalização.

O período inicial de entrada para o lar é pautado por memórias que parecem sugerir tratar-se de um acontecimento muito significativo e vivido com grande intensidade. Assim, alguns idosos relatam memórias positivas, associadas a sentimentos de segurança, pertença e suporte.

“(...) acho que foi tudo positivo! No primeiro dia, naturalmente a gente recorda um bocadinho aquilo que ficou. Logo que aqui fiquei, cheguei, senti-me segura."(ID03)

“(...) conviver mais, ajudar mais. E... e isso.. a gente vai criando laços de amizade. Quando a gente depois está doente, ajuda-nos muito, porque nos ajuda a não ficar numa solidão extrema."(ID09)

Outros participantes descrevem memórias desse período inicial pautadas por tristeza, stress, revolta e insegurança.

"Más, contrariada. Muito mau (choro); pior dia da minha vida (...). Tenho uma recordação má porque eu não me adapto a isto."(ID01)

"Lembro-me, entrei no dia 30 de abril, e... às oito e meia da noite, para não encontrar ninguém. Não queria...não queria encontrar ninguém por o caminho... Só vim às oito e meia, assim não encontrei!'(ID05)

Muito provavelmente associada à natureza das memórias, para alguns idosos a institucionalização trouxe vantagens nomeadamente em termos do estabelecimento de novas relações interpessoais, oportunidades de aprendizagem, proteção, suporte e companhia/acompanhamento. Mas outros idosos identificaram desvantagens, uma vez que perderam privacidade e experienciaram um desfasamento acentuado entre a vivência em casa e no lar.

“Adaptei-me bem porque... porque... prontos... tá tudo... encontrei aqui, vá lá uma família (silêncio), de manhã... a gente ia lá em baixo almoçar, tomar o pequeno almoço, almoçar, jantar, vinha para aqui, ia para a rua e.. fazia a minha vida como se fosse a minha casa."(ID012)

"Não tenho privacidade nenhuma! Eu em casa podia dormir sem roupa... mas aqui não posso dormir sem roupa."(ID01)

A vivência do processo de institucionalização pareceu possuir um potencial de aprendizagem para alguns participantes, uma vez que conseguem formular orientações no sentido de ajudar futuros residentes no processo de entrada no lar, de forma a lidar positiva e adaptativamente com esse acontecimento. Assim, alguns idosos salientam a postura a adoptar no lar que deve caraterizar-se pela descrição, já outros chamam a atenção para a relevância de a entrada para o lar ser uma decisão planeada, na qual a pessoa deve ter um papel ativo.

"A gente antes de ir para o lar tem de pensar bem daquilo que vai fazer, e decidir por si! E depois pronto, pode haver coisas que não agradam muito bem, mas depois também se habituam."(ID07)

"Dava-lhe o conselho de ter esperança de melhorar o ambiente depois de aqui estar, a gente quando entra parece 
que está tudo mal, e depois vai-se aguentando, vai-se melhorando, vai-se tendo melhor, melhor atividades, melhor convívio, eu tenho aqui muita gente que era minha conhecida lá fora, e agora esta cá mas também tenho outras que nunca conheci e são amigas!'(ID014)

Por fim, os idosos mostram também capacidade de formular sugestões de melhoria no funcionamento do lar de modo a aumentar a qualidade dos serviços e o bem-estar dos residentes. Globalmente, as melhorias orientam-se para o contexto, nomeadamente ao nível da criação de novos espaços ou atividades, melhoria em determinados serviços, especialmente a alimentação, e melhoria da relação idosocolaboradores. São também apresentadas referências que apontam no sentido de um papel mais ativos dos idosos no funcionamento do lar, com a introdução, por exemplo, de uma caixa de sugestões.

"Primeira coisa que mudava era liberdade às pessoas de sair e entra às horas que quisessem e que pudessem, mas liberdade, não era só sair debaixo daquele horário, bem e depois organizava grupos que trabalhassem para bem da casa, para bem da comunidade daqui da casa."(ID011)

"A comida, por exemplo. Aqui ninguém passa fome... nesta casa. Não há fome. Mas a comida é pouco pensada, muito repetida."(ID04)

\section{Discussão}

Da análise dos resultados é possível verificar que o conteúdo das entrevistas é atravessado pelo posicionamento de cada idoso face à experiência pessoal do processo de institucionalização, especificamente a fase que antecedeu a entrada para o lar e o período imediatamente posterior, nomeadamente o grau de envolvimento e autonomia do idoso na tomada de decisão, os motivos de institucionalização, as emoções vivenciadas ao longo do processo de tomada de decisão, os aspetos que facilitaram e/ou dificultaram o processo, e as memórias e aprendizagens decorrentes, transformadas em sugestões de mudança e orientações para novos residentes. Globalmente, a experiência de entrada no lar parece constituir-se como um acontecimento gerador de mudança, capaz de ativar competências, recursos e estratégias no sentido de lidar com as mudanças internas e externas desencadeadas. Para a maioria dos participantes claramente a sua vida ficou diferente após a vivência desse acontecimento, sendo relativamente evidente a existência de "um antes" e "um depois" da entrada no lar.

À semelhança da literatura prévia no domínio, também para a maioria dos participantes, a institucionalização foi desencadeada por um acontecimento, sendo que os principais motivos apresentados são similares aos identificados em outros estudos (e.g., Pimentel, 2001; Reedetal., 2003; Sousaetal., 2004), nomeadamente problemas de saúde, solidão, e problemas habitacionais. Importa destacar que para a globalidade dos idosos a institucionalização surgiu como a última alternativa depois de esgotadas todas as possibilidades para continuar a viver em casa. Independentemente do motivo subjacente à institucionalização, esse é um acontecimento conotado por tonalidades emocionais distintas à semelhança do que foi salientado por Pimentel (2001). Identificamos um grupo em que a decisão de entrada para o lar foi acompanhada de sentimentos positivos - satisfação, liberdade, bem-estar, despreocupação, e um outro grupo em que a tonalidade emocional foi claramente negativa - tristeza, saudade, sofrimento, revolta, infelicidade. Essa tonalidade emocional está associada ao grau de participação do idoso na tomada de decisão de entrada no lar.

Os nossos resultados parecem reforçar a relevância do envolvimento do idoso na tomada de decisão na continuidade dos trabalhos de Reed et al.(2003). Também no nosso estudo encontramos participantes que tiveram um envolvimento ativo na tomada de decisão, projetando o ingresso no lar como um acontecimento previsível e desejável na sua vida, tendo mesmo escolhido antecipadamente o lar onde iriam viver. Outros apresentam um envolvimento ativo no processo, no entanto a vinda para o lar não foi planeada, sendo precipitada por um acontecimento imprevisto que cria a necessidade da institucionalização. E, finalmente, um outro grupo que assumiu uma postura passiva, sendo a decisão da responsabilidadede familiares. Claramente, o modo como a decisão de institucionalização se processa parece revelar-se determinante no processo de transição e na capacidade de adaptação, muito provavelmente porque os idosos que preparam e decidem a entrada para o lar têm tempo para antecipar e preparar a mudança, munir-se dos recursos relevantes e mantêm a percepção de controlo sobre si e o que lhes acontece.

Por fim, os resultados obtidos salientam a relevância de aspectos ambientais para o (in)sucesso da institucionalização. Efetivamente, os idosos reconhecem o contributo para a adaptação ao lar de aspectos ambientais como localização geográfica, organização e funcionamento interno, relação com colaboradores, tipo de atividades, níveis de privacidade, entre outros. Para alguns participantes, o facto de ser permitido fazer-se acompanhar de objetos pessoais no ingresso no lar, ou dispor de um quarto individual, parece ter reduzido o nível de pressão do ambiente, aumentando o sentimento individual de competência (Lawton \& Nahemow, 1973; Lawton, 1977) e, por isso, aumentando também a "docilidade ambiental" (Lawton, 1977). Por outro lado, também o tipo e diversidade de atividades proporcionadas foram apontadas como facilitadores, mais uma vez a leitura ecológica parecenos relevante, pois dessa forma o ambiente lar está a exercer uma das funções propostas por Lawton (1975) - estimulação. Já outros participantes referiram como dificuldades/ obstáculos as rotinas estandardizadas e os conflitos com os colaboradores, nesse sentido parece-nos que uma aparente rigidez do contexto poderá ser fonte de excessiva pressão sobre os idosos, originando sentimentos de mal-estar (incompetência) (Lawton \& Nahemow, 1973; Lawton, 1975).

Em síntese, a institucionalização ao lar, na perspectiva dos idosos, constitui-se como um acontecimento desencadeador de um processo de transição que nem sempre culmina num resultado adaptativo com a construção de novos papéis de vida, estatutos e relações. Efetivamente, apesar de ser um acontecimento com alguma probabilidade de ocorrência na velhice, é percebido pelos participantes como fonte de mudança, podendo globalmente identificar-se dois padrões de mudança: um padrão com conotação positiva cujo resultado é a melhoria e a adaptação; e um padrão com conotação 
negativa cujo resultado é a insatisfação e a inadaptação. Parece-nos que ao adotar uma abordagem fenomenológica, assente numa leitura qualitativa, permitiu "escutar" um dos atores principais nesse processo - os idosos - e deste modo validar de alguma forma a experiência e a narrativa de cada participante. A esse propósito parece-nos pertinente salientar alguns aspetos do nosso trabalho: (1) a diversidade dos resultados que reforça uma das principais condições da velhice e do envelhecimento -a heterogeneidade; (2) o foco na experiência percebida e narrada pelo idoso, bem como a análise e a reflexão decorrentes da experiência; (3) o lugar de determinadas condições intra, interpessoais e contextuais na (in)adaptação ao lar; e (4) o potencial para a intervenção gerontológica neste domínio.

\section{Referências}

Alcântara, A. O. (2004). Velhos institucionalizados e família: entre abafo e desabafos. Campinas: EditoraAlínea.

Baltes, P. B., Lindenberger, U., \& Staudinger, U. M. (2006). Lifespan theory in developmental psychology. In W. Damon (Series Ed.) \& R. M. Lerner (Vol. Ed.), Handbook of child psychology: Theoretical models of human development (pp. 234-256.). New York: Wiley.

Barenys, M. P. (1990). Residencias de Ancianos - Análisis Sociológica. Barcelona: Fundacion Caixa de Pensions.

Brammer, L., \& Arengo, P. (1981). Intervention strategies for coping With transition. The Counseling psycology, 9(2), 19-36.

Bula, L. C., Mediondo, Z. M. (2004). Velhice, dependência e vida cotidiana institucional. In I. A. Cortelleti, M.B. Casara, V. B. M. Herédia (Eds.), Idoso asilado: um estudo gerontológico (pp. 87-97). Porto Alegre: Edipucrs.

Carp, F. \& Carp. A. (1984). A complementary/congruence model of well-being or mental health for community elderly In I. Alteman, J. Wohlwill\& M. Lawton (Eds.), Elderly people and the environment (pp. 87-98). New York: Plenum Press.

Creswell, J. (2009). Research design: Qualitative, qualitative and mixed methods approaches. Londres: Sage.

Felner, R., Farber, S., \& Primavera, J. (1983). Transitions and stressful life events: A model for primary prevention. In R. Felner, S. Farber \& J. Primavera (Eds.), Preventive psychology (pp. 123-135). Nova York: Pergamon Press.

Ferreira, M. L. M. (2003). Memória e velhice: do lugar da lembrança. In M. Barros (Ed.), Velhice ou terceira idade? Estudos antropológicos sobre identidade, memoria e política (pp. 236). Rio de Janeiro: Editora.

Gill, T. M., Robinson, J. T. Willams, C.S. \& Tinetti, M. E. (1999). Mismatches between the home environment and physical capabilities among community-living older persons. Journal of the American Geritric Society, 47(I), 88-92.

Goffman, E. (1996). Manicómios, prisões e conventos. S. Paulo: Perspectiva.

Graeff, L. (2007). Instituições totais e a questão asilar Uma abordagem compreensiva: Estudo interdisciplinar envelhecimento. Porto Alegre: Editora.

Groger, L. (1995). A nursing home can be home. Journal of Ageing Studies, 9, 2, 137-153.
Guedes, J. (2008, junho). Desafios identitários associados ao internamento em lar. Atas do V Congresso Português de Sociologia, 339, 2-12.

Kahana, E., Liang, J.,\&Felton, B. (1980). Alternative models of person-environment fit: predictions of morale in three homes for the aged. Journal of Gerontology, 35, 584-595.

Lawton, M.P., \& Nahemow, L. (1973). Ecology and the aging process. In C. Eisdorfer\& M.P. Lawton (Eds.), Psychology of adult development and aging (pp. 619-624). Washington: American Psychological Association.

Lawton, M. P. (1975). The Philadelphia Geriatric Center Morale Scale: a revision. Journal of Gerontology, 30, 85-89.

Lawton, M. P. (1977). The impact of the environment on aging and behavior. In J. E. Birren\& K. W Schaie (Eds.), New dimensions in environmental design research (pp. 276-301). New York: Van Nostrand Reinhold.

Lawton, M. P.(1989). Measuring caregiving appraisal. Journal of Gerontology: Psychological Sciences, 44, 61-71.

Paúl, C. (2005). Envelhecimento e Ambiente. In L. Soczka (Ed.), Contextos humanos e psicologia ambiental (pp. 247-268). Lisboa: Fundação Calouste Gulbenkian.

Pimentel, L. (2001). O lugar do idoso na familia: contextos e trajectorias. Coimbra: Quarteto.

Reed, J., Cook, G., Sullivan, A., \&Burridge, C. (2003). Making a move: care home residents experiences of relocation. Ageing and Society, 23, 225-241.

Santini, R. E. (2000). Operfil do idoso na sua unidade domestica -o Caso de Viçosa. (Unpublished master's thesis) Universidade Federal de Viçosa, Viçosa, Brasil.

Schlossberg, N. (1981). A model for analyzing human adaptation to transition. The Counseling Psychologist, 9,(2), 2-18.

Schlossberg, N., Water, E., \& Goodman, J. (1995). Counseling adults in transition - Linking practice with theroy. Nova Yorque: Springer.

Sousa, L., Figueiredo, D., \& Cerqueira, M. (2004). Envelhecer em familia: Os cuidados familiares na velhice. Porto: Ambar.

Wenger, G. (2001). Interviewing old people. In J. F. Gubrium\& J. A. Holstein (Eds.), Handbook of interview research: Context and method (pp. 259-2278). London: Sage.

Recebido em 08.04.2014

Primeira decisão editorial em 11.06.2014

Versão final em 10.07.2014

Aceito em 04.11.2014 